\title{
Modeling and simulation of a solar flat plate collector as an air heater considering energy efficiency
}

\author{
F. Esmailie, H. Ghadamian a And M. Aminy \\ Department of Energy, Materials and Energy Research Center (MERC), P.O. Box 14155-4777 Tehran, Iran
}

Received 8 March 2014, Accepted 2 June 2014

\begin{abstract}
The present research study includes thermal energy performance analysis of a flat plate solar collector, in order to cover a sensitivity analysis about effective variables contributed to performance increasing approach. To obtain that, energy and momentum governing equations on a flat plate thermal collector were developed to achieve air output temperature and velocity profiles both in model and experiment. The model theory is validated with experiments by a set of flat plate thermal collectors, those located in $\left(35^{\circ} 44^{\prime} 35^{\prime \prime} \mathrm{N}, 50^{\circ} 57^{\prime} 25^{\prime \prime} \mathrm{E}\right)$ coordinates and then were applied to carry out experimental activities. Quantitative results depicted that the mean difference between predicted and measured output air temperature in natural and forced convection scenarii is $1.47{ }^{\circ} \mathrm{C}(3.5 \%)$ and $0.9{ }^{\circ} \mathrm{C}(1.5 \%)$, respectively; however earlier research works and studies mentioned in literature, include error percentages in the range of $4-10 \%$. Another quantification about, the average error percentages of estimated amounts of output air velocity profile values in natural and forced convection scenarii is $9 \%$ and $4 \%$, respectively. This issue realizes the developed model in forced convection scenario more accurate than natural convection scenario.
\end{abstract}

Key words: Energy balance / momentum balance / sensitivity analysis / numerical methods / solar energy

\section{Introduction (Survey and tutorials)}

A steady state model that applies simplifying assumptions such as constant heat loss coefficient and capacity has been developed by Bliss [1]. In spite of that, several researches are developed engaging with energy balance differential equations on flat plate solar thermal collectors based on transient conditions which have been solved numerically. As a general statement, these developing models, rarely but not accurately, predict output temperature of the media flows through the collector. Regarding this issue, Aboul-Enein et al. [2], Janjai et al. [3] and Sami et al. [4] have validated their model results coordinating with experimental data. Among them, only the report of Janjai's model conducts maximum error percentage of $10 \%$. Benamun et al. [5], Garg et al. [6] and Jain et al. [7] develop a model in thermal flat plate solar collector which was implemented in solar dryer's application, but they didn't mention any model validation regarding experimental results to approve the model verifications. Likewise, an energy balance differential equation in a

${ }^{a}$ Corresponding author: h.ghadamian@merc.ac.ir steady state condition was written on solar tunnel dryers by Hossein and Bala [8]. These equations were developed in forced convection mode and predict the air output temperature of the solar collectors, but face again less of data validation and reconciliation of the model [8]. There are some more complete studies that include all model and experiments together to cover the mentioned subject. For instance, Simate compared two types of solar dryers in natural convection mode, which solved a set of differential equations on solar collectors and dryer's bed and results show acceptable agreement with experimental data. The point of this study is only consideration at the natural convection scenario and does not consider forced convection [9]. The other related comprehensive study is an efficient model that developed by Gao et al. [10], on a glazed and unglazed solar collectors. This model was written based on steady state condition and take place in cold climate. As a proven issue, in the case of unglazed collectors, model results were completely compared with experimental findings, the greatest difference between the model and experimental results was equal to $0.55^{\circ} \mathrm{C}$ that shows well accurate. As a merit, dimensionless parameters 


\section{Nomenclature}

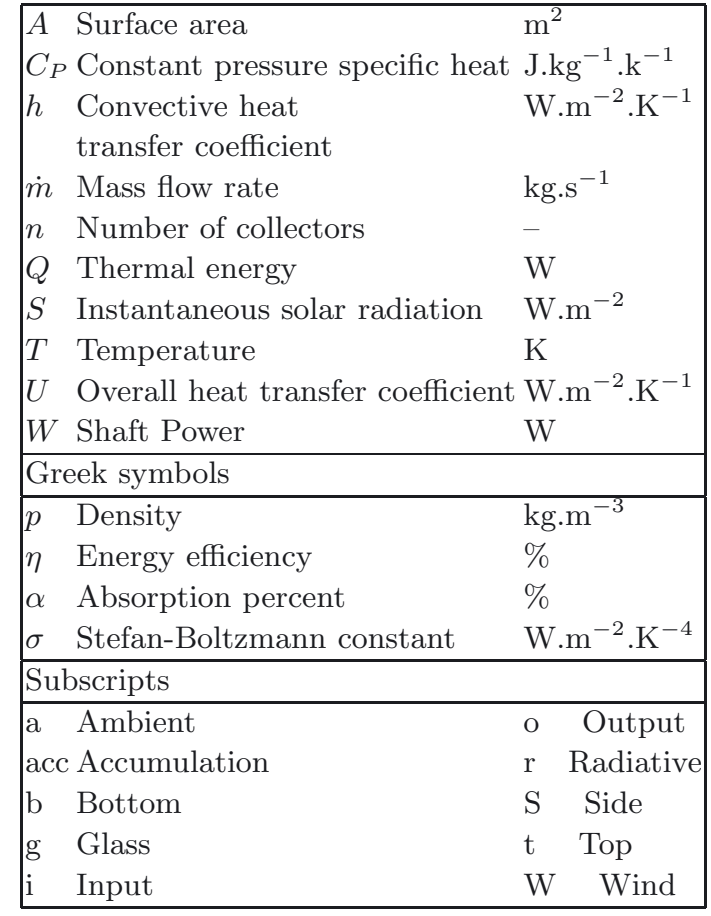

applications within simulation methods would be greatly useful in order to change the models to be applicable for a wide range of operating conditions. Likewise, air output temperature in a solar thermal collector was defined in a function of mass flow rate and length to width ratio of a collector; with Britto et al. [11]. Regarding such method, the massive initial calculations, which shall be done to convert initial data to dimensionless format, will be increased significantly. Some research findings express that solar thermal collectors can be simulated regarding with software's applications, such as TRNSYS. TRNSYS simulates most types of solar systems; Delisle et al. [12] simulated a BIPV/T air collector with TRNSYS software. The percentage of RMSE for output air temperature has been reported to be around $3.75 \%$; nevertheless it requires significant amount of skill to operate, not accurate enough, as shown. Air output velocity and its influence on the collector's efficiency were not reported in none of the models which mentioned above. In the general application of integrated solar collectors and dryers, output velocity and humidity of air are important factors, thus, the lack of these two parameters in previous studies outputs seems to be a restriction for comprehensive studies. In addition to that, sensitivity analysis of effective parameters and the way that they would effect on system must be exactly recognized and analyzed to control and imply the effectiveness parameters for enhancing system's energy efficiency. Only Shahsavar and Ameri designed and modeled a direct-coupled PV/T air collector [13]. They developed an energy balance on solar collector and solved it with numerical methods. One of the significant points of their research is predicting air output velocity regarding heat transfer phenomena studies. Maximum standard percentage deviation error (e) for air output temperature and velocity were $3.93 \%$ and $7.28 \%$ respectively, those are in acceptable range. Some more complete done researches, include natural and forced convection airflow in windows was analyzed using numerical simulation of heat transfer by Ghadimi et al. [14]. They studied variations of velocity and temperature profiles with geometrical parameters. The energy model which developed in this study can be useful to develop energy model in enclosures such as solar flat plate collectors. Ghadamian et al., studied energy models of double skin-facades, that solved both analytically and numerically $[15,16]$. The governing equations and solution methods within these systems are similar to solar flat plate collector application.

Considering all mentioned literature and contributed results, the main duty of solar collector is defined to absorb the direct radiation and convert it to thermal energy. It is supposed to, the received energy, transfer to medium (for instance water, air or oil); that would be applied directly or indirectly. Flat plate thermal collectors are generally focused contributed to their simple application and competitive final price. Several cases of residential and industrial use; such as solar dryers, solar desalination, solar water heating systems (like domestic hot water) and solar space heating; are commonly reference facts of its applications. Based on this research requirement, the application related to solar dryer integrated with solar flat plate collectors is considered. The process of drying is started with the heated air passing through a solar collector, as a media, in order to enter the dryer's bed. Through dryer bed, working medium accelerates the moisture content evaporation from surface of particles. In order to achieve a well accurate operative collector, it is necessary to model the mentioned systems and predict the performance of this equipment. Again it is stated that flat plate solar collectors' configuration studies are narrow and its analysis requires a complex dynamic, as a must. By this mean, many parameters affect the solar flat plate collectors' energy performance, as well. Investigations through this area of research, explain still few of them studied momentum equations integrated with other transfer phenomena studies. Generally solar collectors and modeling contributions are including heat transfer phenomena just focused on thermal energy balance except velocity profiles studies. Thus, most of these studies do not evaluate the medium's output velocity. In the subject of integration, related to collectors' studies within other working equipment in several applications like dryers, heaters, HVAC systems and etc.; calculating medium's output velocity profile, depends on collector geometry and local conditions, is an obligatory request to reply on comprehensive models. Meteorological data like wind velocity, solar radiation and ambient temperature are required as input variables; those should be well verified to models. In most cases for reducing experimental activities, the required data have been collected from local meteorological stations. Based on differente distance situations of Pilot studies and metrological stations, the related input data have not enough precise. 
Table 1. Characterization of solar collector unit.

\begin{tabular}{lrlr}
\hline Description & Value (unit) & Description & Value (unit) \\
\hline Height & $2(\mathrm{~m})$ & Aluminum plate thickness & $0.002(\mathrm{~m})$ \\
Width & $0.9(\mathrm{~m})$ & Galvanized plate thickness & $0.002(\mathrm{~m})$ \\
Input cross-section length & $0.78(\mathrm{~m})$ & $\begin{array}{l}\text { Outlet cross-section area } \\
\text { in natural convection mode }\end{array}$ & $0.0177\left(\mathrm{~m}^{2}\right)$ \\
& $0.03(\mathrm{~m})$ & $\begin{array}{l}\text { Outlet cross-section area } \\
\text { in forced convection mode }\end{array}$ & $0.0198\left(\mathrm{~m}^{2}\right)$ \\
Input cross-section width & $0.004(\mathrm{~m})$ & $\begin{array}{l}\text { Solar collector slope } \\
\text { Glass thickness }\end{array}$ & $45^{\circ *}$ \\
Size of the gap between the glass & $0.048(\mathrm{~m})$ & Glass emittance & 90 \\
and the absorber plate & $0.007(\mathrm{~m})$ & Absorber plate emittance & \\
Absorber plate thickness & $0.002(\mathrm{~m})$ & & 95 \\
Foam plate thickness & & & \\
\hline
\end{tabular}

* The annual appropriate slope for solar thermal collectors is equal to location latitude.

Energy modeling of the solar thermal collectors to predict the output velocity and temperature profiles of air is the principle goal of the present study. Distinctive points of this study are:

- prediction of the output air velocity profile with acceptable and accurate precision,

- sensitivity analyses of effective parameters on air output profiles contributed to velocity and temperature, and

- study of the effectiveness of selected variables on the system's efficiency.

\section{Experimental set-up}

A set of flat plate thermal collectors, those located in $\left(35^{\circ} 44^{\prime} 35^{\prime \prime} \mathrm{N}, 50^{\circ} 57^{\prime} 25^{\prime \prime} \mathrm{E}\right)$ coordinates, were applied to carry out experimental activities. This system consists of a plenum duct that integrates the collectors exit vent, a centrifugal fan and a photovoltaic DC-motor, to drive the air through with collectors in forced draft status. The exact characteristics of this system are described in Table 1, and a schematic diagram of the system is shown is Figure 1, accordingly.

\section{Energy modeling and simulation}

In the present research study an energy model was developed on a flat plate solar thermal collector. Air output temperature and velocity profiles can be predicted by this developed model. In natural convection scenario, in order to develop the energy balance on the system, it has been assumed that, solar radiation is the most important share of energy, which is received by the system; besides, in forced convection scenario, a mechanical energy implies to the medium by centrifugal fan. With the aim of system energy balance, the thermal energy losses by glasses, all collector sides have been calculated and subtracted from the input energy. With this issue, the remain is assumed to be accumulated energy part transferred to medium (moist air in this case) completely. Related governing equations are given in Table 2, regarding further explanations of heat transfer. For more significant clarifications, Figure 2 is presented on the basis of thermal energy modeling that contains various heat transferring elements.

It should be notify that, considering some assumptions are necessary to solve simultaneously the mentioned governing equations, those are listed below:

- the process is assumed steady state,

- air is in thermal equilibrium with absorber plate,

- air is stated as an ideal gas.

\subsection{Solution method}

To obtain the air output temperature and velocity profiles, a set of equation packages must be considered for solution simultaneously. Owing to the fact that, the equations are coded in open-source-code software (EES) that employs Newton-Raphson method to aggregate a set of nonlinear equations; were adopted to solve the equations simultaneously. The designated algorithm of solution method is demonstrated in Figure 3.

Secondary assumptions are considered to simplify the model, as following:

1- Temperature profile of flowing air under the collector is assumed to be equal to the ambient temperature (this is based on the measured experimental set of temperature measured points and estimated profiles).

2- In natural convection scenario it is assumed that the related outflow air pressure is equal to the inflow air pressure (in this situation the collector entrance and exit is faced to the ambient and there is no variation of pressure, so pressure is assumed to be equal to ambient pressure. In addition to that, buoyancy force due to the small gradient pressure and low height of collector compensate the surface pressure loss and do not include significant effect on pressure variations). 

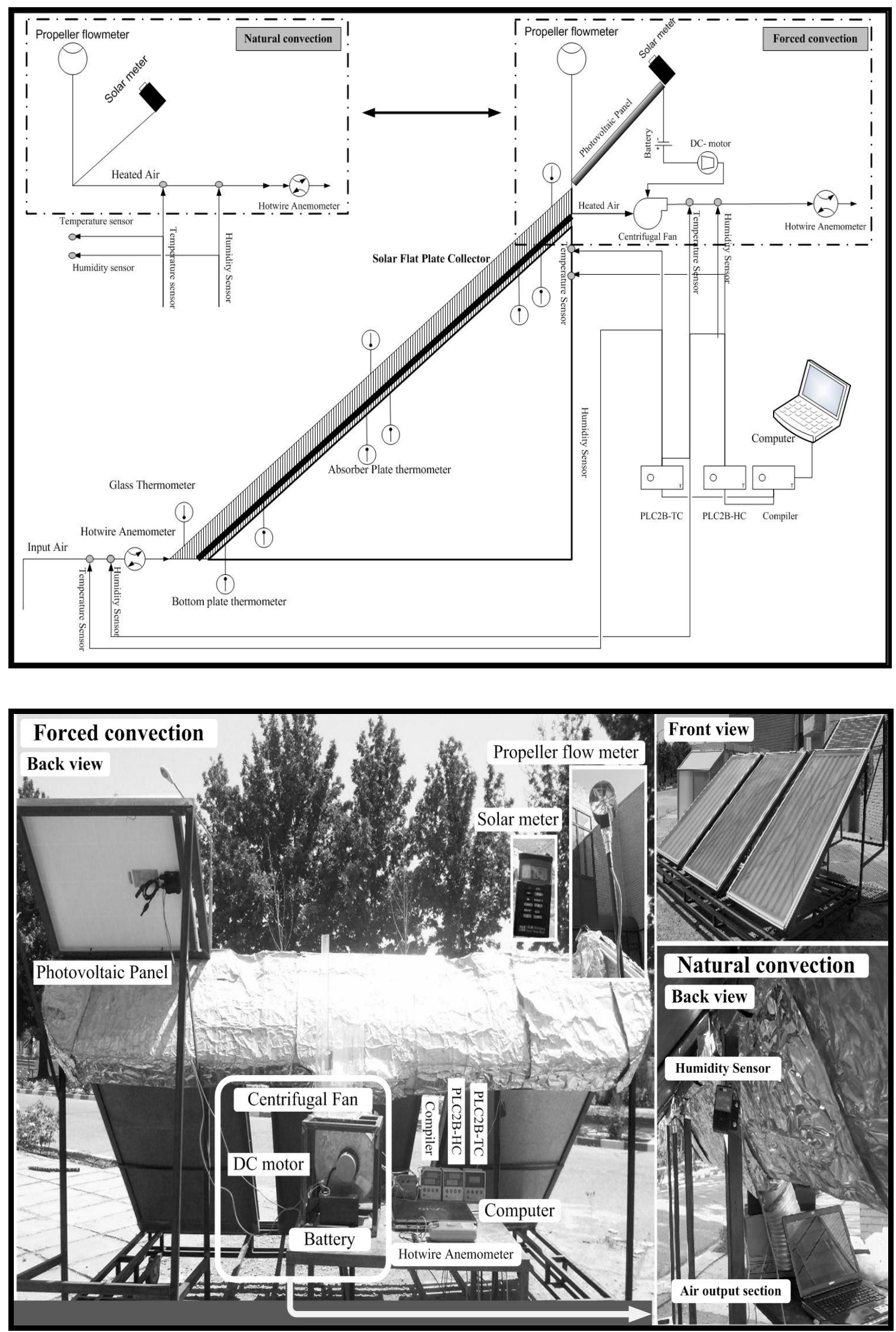

Fig. 1. A schematic diagram of solar air heater collectors' set-up. 


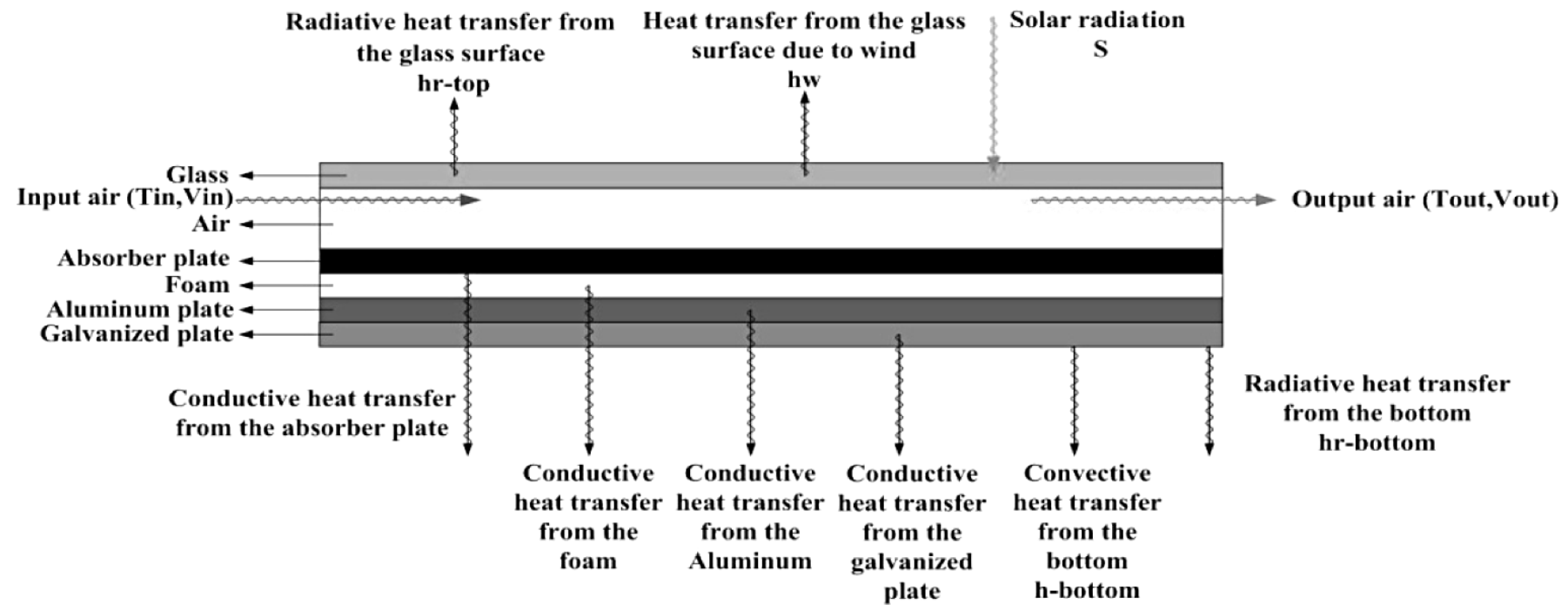

Fig. 2. Schematic diagram of various solar collector heat transfer elements.

Table 2. Governing equations of model.

\begin{tabular}{|c|c|c|}
\hline Number of equation & Description & Equation \\
\hline \multirow{2}{*}{ (1) } & \multirow{2}{*}{ Energy loss from glass } & $U_{t}=h_{w}+h_{r t}$ \\
\hline & & $Q_{t}=U_{t} A_{t}\left(T_{g}-T_{a}\right)$ \\
\hline \multirow{2}{*}{ (2) } & \multirow{2}{*}{ Energy loss from corner side } & $U_{s}=h_{W}+h_{r s}$ \\
\hline & & $Q_{s}=U_{s} A_{s}\left(T_{s}-T_{a}\right)$ \\
\hline \multirow{2}{*}{ (3) } & \multirow{2}{*}{ Energy loss from top side } & $U_{t s}=h_{W}+h_{r t s}$ \\
\hline & & $Q_{t s}=U_{t s} A_{t s}\left(T_{t s}-T_{a}\right)$ \\
\hline \multirow{2}{*}{$(4)$} & \multirow{2}{*}{ Energy loss from bottom side } & $U_{b s}=h_{W}+h_{r b s}$ \\
\hline & & $Q_{b s}=U_{b s} A_{b s}\left(T_{b s}-T_{a}\right)$ \\
\hline \multirow{2}{*}{$(5)$} & \multirow{2}{*}{ Energy loss from bottom } & $U_{b}=h_{W}+h_{r b}$ \\
\hline & & $Q_{b}=U_{b} A_{b}\left(T_{b}-T_{a}\right)$ \\
\hline (6) & Sum of energy losses & $Q_{\text {Loss }}=Q_{t}+Q_{t s}+Q_{b s}+Q_{b}+2 \times Q_{s}$ \\
\hline (7) & Accumulated energy in glass & $Q_{a c c g}=\alpha \sigma A_{g}\left(T_{g}^{4}-T_{a}^{4}\right)$ \\
\hline (8) & Total energy loss from collector & $Q=1.2 \times Q_{\text {Loss }}+Q_{a c c g}$ \\
\hline (9) & Total transferred energy to process fluid & $Q_{a c c}=(S \times A)-Q=\dot{m} C_{p}\left(T_{o}-T_{i}\right)$ \\
\hline$(10)$ & Mass balance & $\rho_{i} A_{i} V_{i}=\rho_{o} A_{o} V_{o}$ \\
\hline$(11)$ & Collector efficiency & $\eta=\frac{\left(\dot{m} C_{p}\left(T_{o}-T_{i}\right)\right)}{(S \times n \times A)} \times 100$ \\
\hline
\end{tabular}

\subsection{Simulation}

The process of simulation based on this research study is defined as following activities:

- developing the governing model,

- building-up the set-up for experimental study,

- testing and measuring the system performance and

- validating model results with measurement procedure.

All of these procedural steps were completely covered in this research study, for further explanations, in the following sections experimental procedures besides model evaluation will be discussed.

\section{Experimental study}

A set of experimental data were planned to evaluate model results; so that one test set of solar collectors was examined both in natural and forced convection scenarii. To cover this purpose, an experimental test plan is prepared to implement the monitoring and measurement activities. It should be focused that, the primary required variables are solar radiation, wind speed, ambient and output temperature profiles and humidity besides the output velocity of the medium. In order to fulfill the mentioned target a set of experiments was carried out in July 2013. During measurement, temperature and relative humidity ratio were obtained using Tamkar PLC2B data 


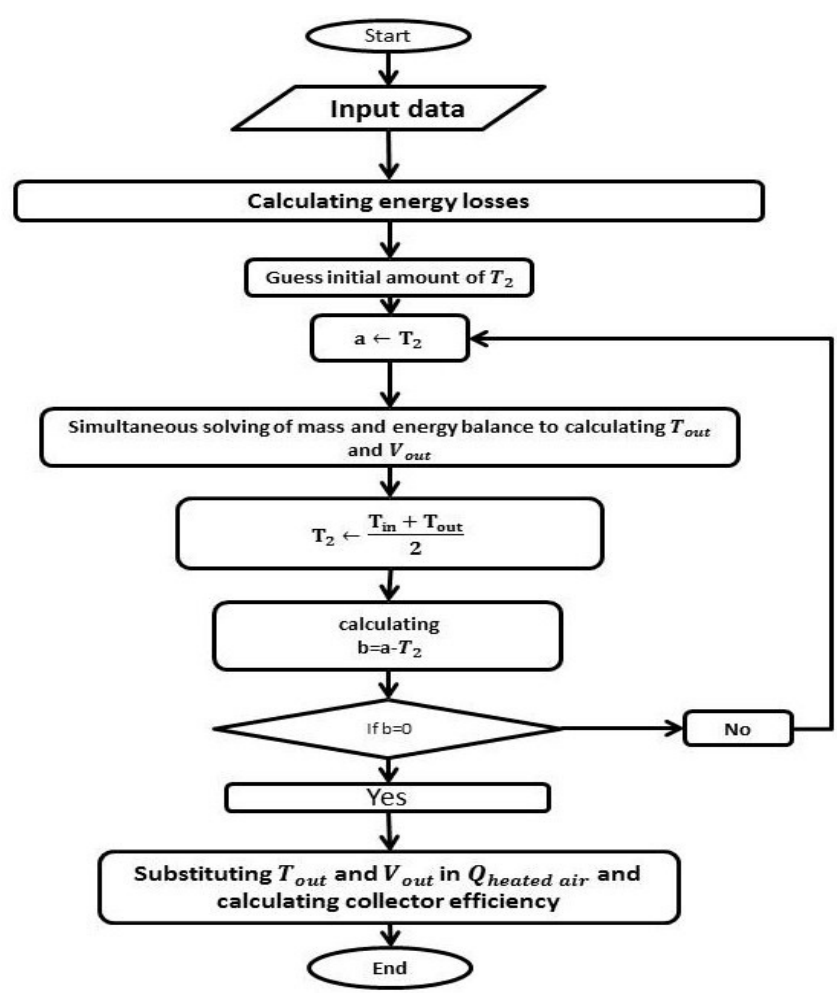

Fig. 3. The algorithm of solution method.

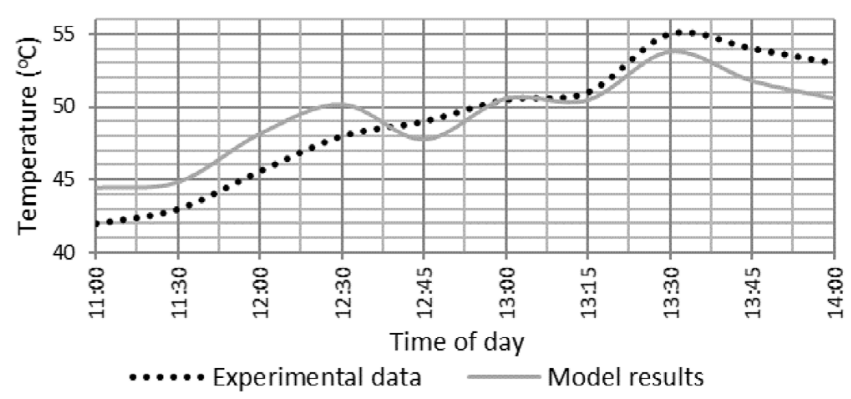

Fig. 4. Output air temperature profile in natural convection scenario.

loggers, ENVIT propeller anemometer was also used to measure wind speed. Likewise, solar radiations were determined by TES 1333R solar meter and also input and output velocity profiles were measured by a TES-1341

\subsection{Experimental results and model validation}

After theoretical code rendering based on the governing equations development, results were compared to the experimental data. Figure 4, shows a comparison between model results and experimental measured data, through a sunny day dated in 27 th of July 2013.

According to Figure 4, it is seen that the model results are in acceptable agreement with measured data. Output air velocity profile in natural convection scenario, increases within the range of $0.01 \mathrm{~m} / \mathrm{s}$, near the wall to

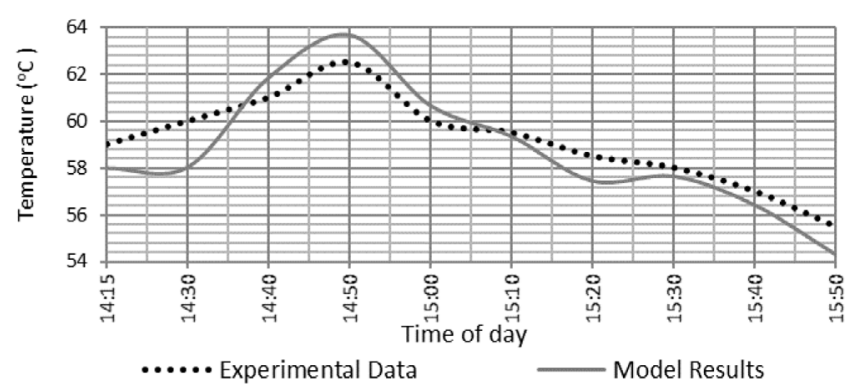

Fig. 5. Output air temperature in forced convection scenario.

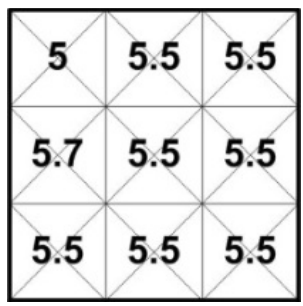

Fig. 6. Output air velocity profile (measured data).

Table 3. Air output velocity profile in natural scenario $(\mathrm{m} / \mathrm{s})$.

\begin{tabular}{ccc}
\hline Time & $\begin{array}{c}\text { Output air velocity } \\
\text { [predicted with model }(\mathrm{m} / \mathrm{s})\end{array}$ & $\begin{array}{c}\text { Output air velocity } \\
\text { [measured }(\mathrm{m} / \mathrm{s})]\end{array}$ \\
\hline $11: 30$ & 0.04 & 0.05 \\
$12: 00$ & 0.05 & 0.05 \\
$12: 30$ & 0.05 & 0.05 \\
$12: 45$ & 0.05 & 0.05 \\
$13: 00$ & 0.05 & 0.04 \\
$13: 15$ & 0.05 & 0.05 \\
$13: 30$ & 0.04 & 0.04 \\
$13: 45$ & 0.05 & 0.05 \\
\hline
\end{tabular}

$0.05 \mathrm{~m} / \mathrm{s}$ in the center of outlet section. Predicted and measured output air velocity is given in Table 3 .

Figure 5 depicts the predicted and measured air output temperature in forced convection mode.

Considering Figure 5, comparison between model and experimental results shows that the predicted air outlet temperature is in acceptable agreement with experimental results. Regarding Figures 4 and 5 comparison, in natural convection scenario, residential time of medium is more than forced convection mode. Based on this issue and as the developed code of theoretical model independent to residential time factor, the accuracy factor of model in forced convection scenario is more proper than natural convection scenario. Output air velocity profile in the exit cross section of centrifugal fan, is planned to be measured in different points. Figure 6, shows a demo about the points where the measurements have been implemented, besides their related values.

About the velocity comparisons, a proper agreement is found between average of measured values and model predicted data, those are $5.46 \mathrm{~m} / \mathrm{s}$ and $5.69 \mathrm{~m} / \mathrm{s}$ respectively; hence that shows model is very well tuned to experiment in this specific category. 


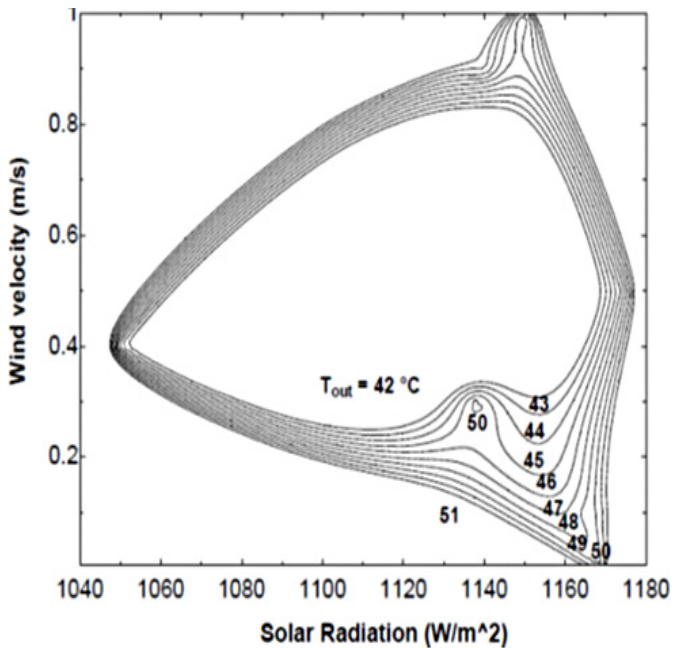

(a)

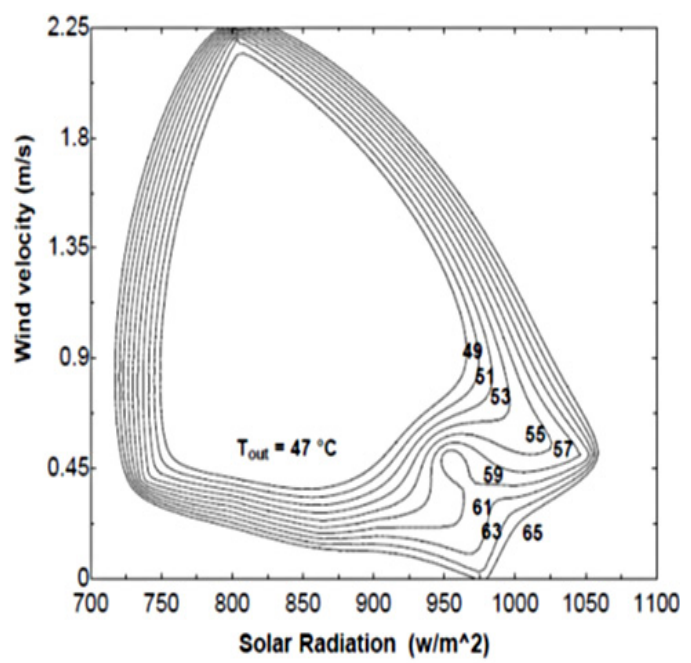

(b)

Fig. 7. The effect of solar radiation and wind speed on the air output temperature ((a) natural, (b) forced convection).

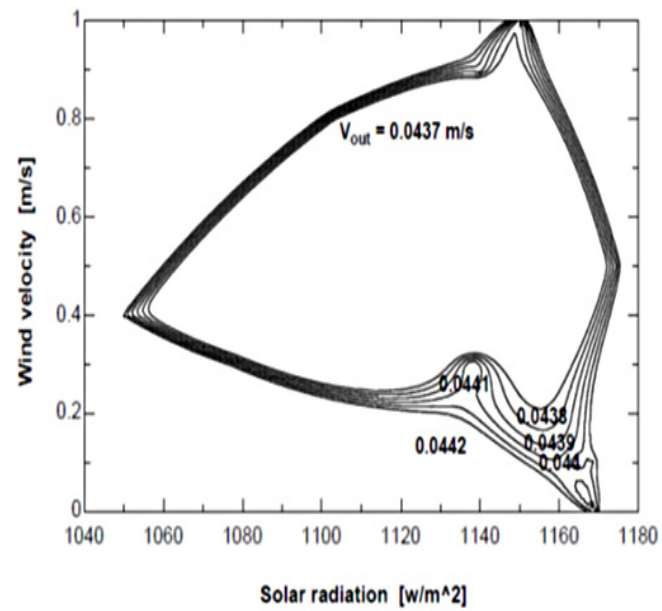

(a)

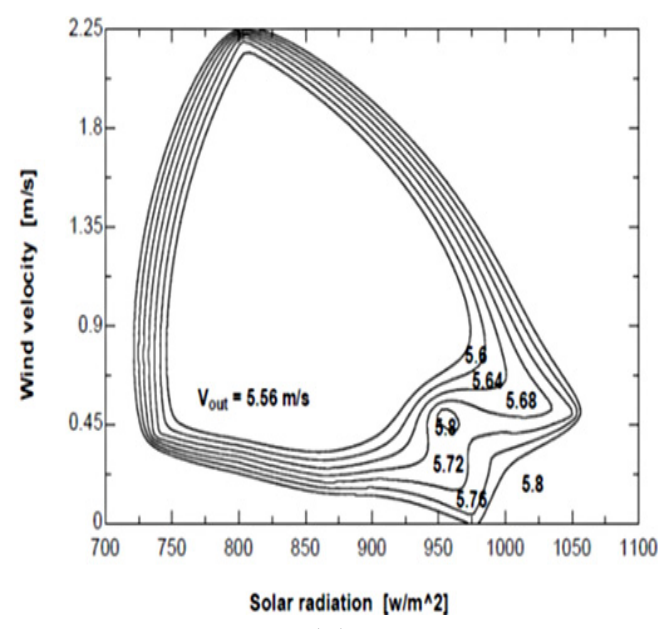

(b)

Fig. 8. Output air velocity profile variations in association with radiation and wind speed ((a) natural, (b) forced convection).

\section{Result and discussions}

Based on previous section results contributed to output velocity and temperature profiles related to different scenarii of natural or forced convection, it is stated that the model covers the validation and experimental agreements. By these means, in this stage, it seems necessary to go through the parametric studies. Regarding those, the model will vary depending on verified input data and bound of variables. In the following section the effect of solar radiation and wind speed on air output temperature and velocity profiles will be discussed. Figures 7 and 8 depict the mentioned terms in natural and forced convection scenarii. In Figure 7, gaps among isothermal curves increase if we compare forced convection with natural convection situation, this issues that, within forced convection scenario the effect of solar radiation and wind speed on output air temperature profile decrease. This is because of the buoyancy effect reduction pending proven driving momentum at forced convection scenario.

In Figure 8, the simultaneous effects of solar radiation and wind speed on air output velocity profile are illustrated.

It also can be found in Figure 8, that the output air velocity profile trends are similar than temperature profile variations. Output air velocity in forced convection scenario is less dependent on solar radiation and wind speed because in this case that is a function of the centrifugal fan speed therefore the effect of buoyancy is negligible.

In the following section the effect of solar radiation and wind speed on output air temperature and collector efficiency will be discussed. Figures 9 and 10 depict the mentioned terms in natural and forced convection scenarii. 


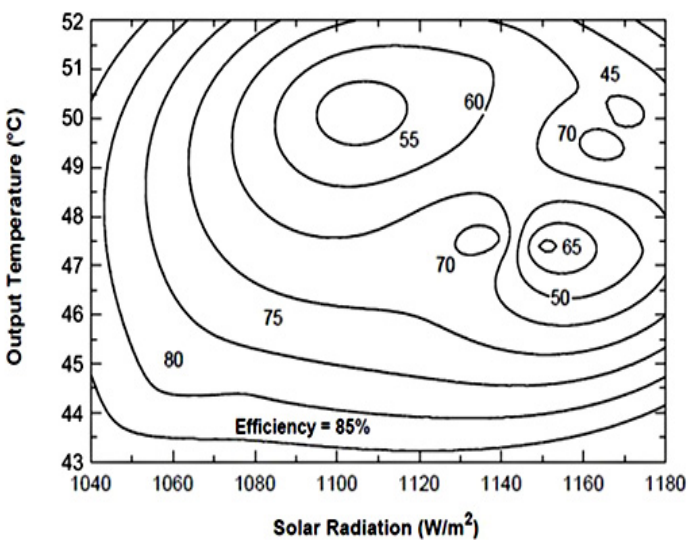

(a)

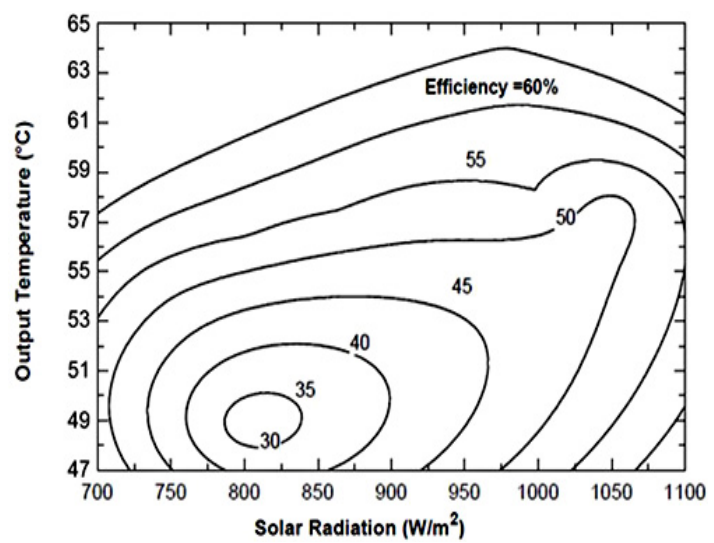

(b)

Fig. 9. Output air temperature and collector energy efficiency variations in association with radiation and wind speed ((a) Natural, (b) Forced convection).

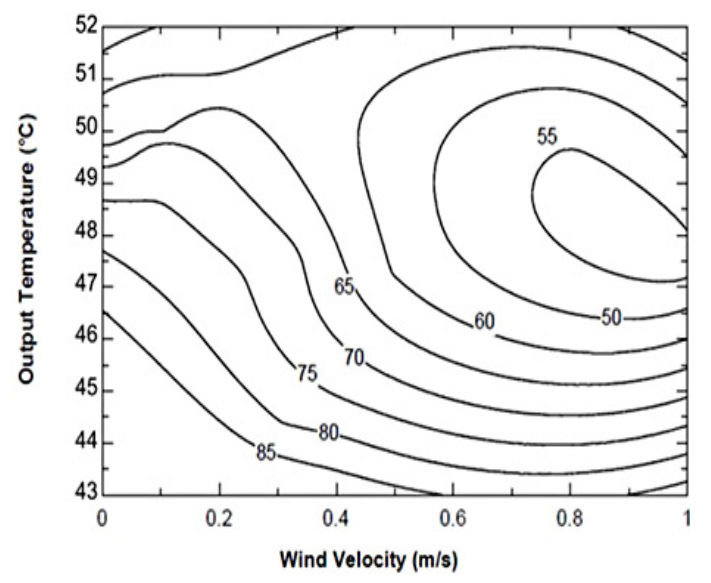

(a)

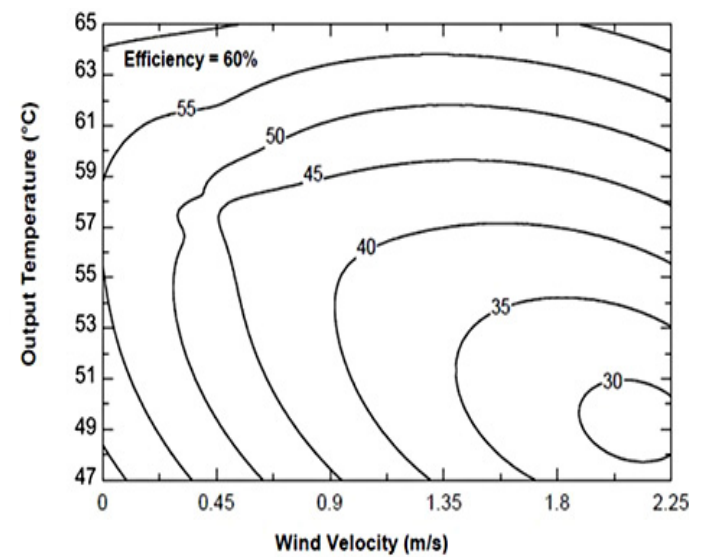

(b)

Fig. 10. Output air temperature and collector efficiency variations versus wind speed ((a) Natural, (b) Forced convection).

The effect of solar radiation on output air temperature and collector efficiency is fully illustrated in Figure 9.

The increase of collector efficiency and the trends are differtent depending on the type of convection scenario. As shown in Figure 9, it has been observed that in forced convection scenario, higher efficiencies occur at lower temperature values. But through with natural convection scenario, temperature decline causes a decrease of the fluid activity, so the fluid remains more time in contact with absorber plate, which consequently yields more in opportunity of receiving energy status. Indeed, the high efficiency in this scenario refers to the down rate of process. To consider more in details, it seems in natural convection status and for temperatures higher than $46{ }^{\circ} \mathrm{C}$, the effect of solar radiation on collector efficiency is sensible; however, in lower temperatures, change in solar radiation does not have significant effect on collector efficiency. In contrast, in forced convection status and temperature lower than $55^{\circ} \mathrm{C}$, the effect of solar radiation variations on energy efficiency is considerable, nevertheless in upper temperatures, variations in solar radiation do not affect the energy efficiency term. Higher efficiencies occur at higher temperatures in forced convection, because in this case, the effect of buoyancy is low and fan sucks the air from the collector. Change in velocity is decided by fan speed, accordingly, in this state the physical peak should not be meaningful, but there should be a mathematical peak that is minimum point forsooth. The Figure 10 demonstrates the collector efficiency helical diagrams versus output air temperature and wind velocity profile variations.

According to Figure 10, in natural convection status and temperatures lower than $46{ }^{\circ} \mathrm{C}$, the effect of wind speed profile on collector efficiency is not considerable, but through with higher temperatures levels, especially when it coordinated within wind speeds upper than $0.5 \mathrm{~m} / \mathrm{s}$, the effect of wind speed on collector efficiency is considerable. Because, in lower temperature bound of variation, wind speed does not lead to considerable heat losses, so the effect of wind speed is 


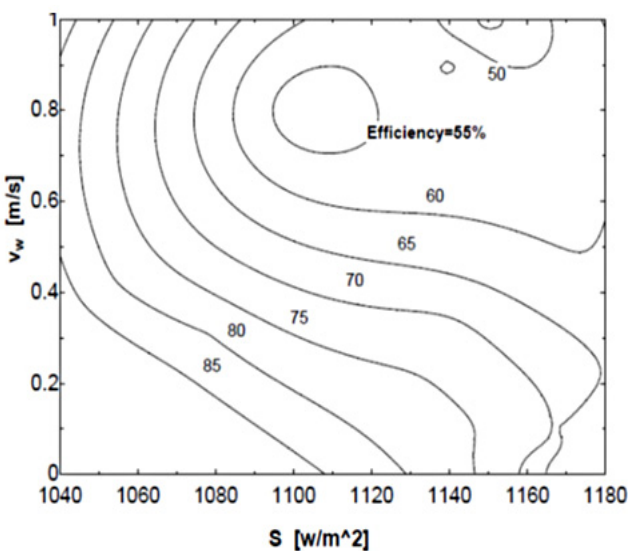

(a)

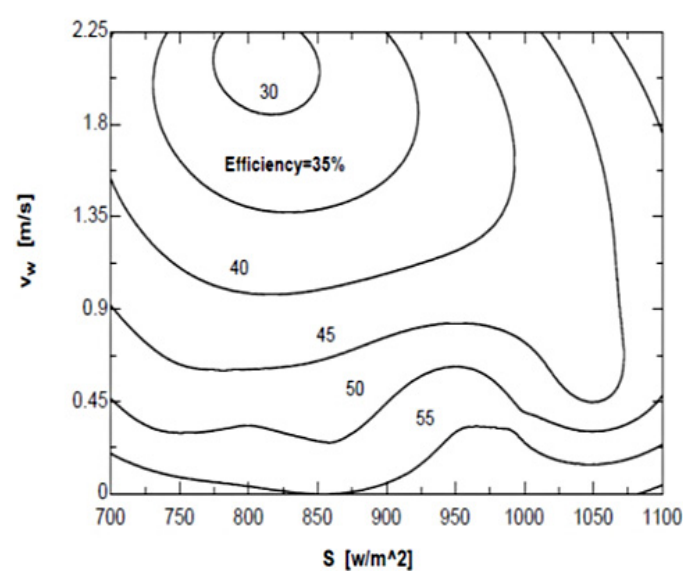

(b)

Fig. 11. Simultaneous effect of solar radiation and wind speed on collector energy efficiency ((a) Natural convection (b) Forced convection).

negligible. In contrast, in forced convection status and temperatures upper than $57^{\circ} \mathrm{C}$, the effect of wind speed on collector energy efficiency is negligible. To consider the interference effects of wind speed and solar radiation on energy efficiency of collector, the simultaneous effects are demonstrated in Figure 11.

Figure 11 definitely depicts that in the natural convection scenario, higher collector energy efficiencies occur in higher solar radiations rates. In fact, in lower radiations, the rate of air heating and consequently the air media momentum are low; hence the residential time to face the air with collector plate is high. By these means, the medium has more time to receive the energy when it compares with forced convection scenario, although in this situation due to the low momentum value of output air, the system does not have its actual performance and the efficiency term does not show the favorable performance, as it needs for further operations. What is more, energy efficiency is as its real concept in forced convection mode; that is, the efficiency in this state shows that how well the system works. As a result, by increasing the solar radiation and decreasing wind speed value, energy efficiency increases, in the same reason, decreasing the wind speed leads to less heat losses and higher efficiency and vice versa. Moreover, in forced convection scenario, surging solar radiation has not significant effect on efficiency, because with increasing the solar radiation, the air output temperature increases, so the numerator and denominator of efficiency term increase approximately equal; as a rough estimation, in this situation the efficiency remains unchanged.

The significant features of the model results are:

- the results of theoretical model are in acceptable agreements with experimental data, as shown in Figures 4 and 5,

- the input solar energy model is supposed to be dynamic; as an advantage, the model has the ability to predict air output temperature and velocity profiles in every second by giving instantaneous solar radiation,
- the model can predict the operation extremes that are applicable to energy system design and,

- sensitivity analysis contributed to the effects of solar radiation and wind speed profiles, on output air temperature and the collector energy efficiency, are other remarkable points of this study which are fully explained in Figures 7 to 11.

\section{Conclusion}

The main aim of the present research study is predicting output air temperature and velocity profiles; to obtain that, a complex energy model, based on heat and momentum transfer phenomena is developed on a flat plate solar thermal collector air heater. To evaluate the model performance, a Pilot is implemented and experimental measured data and theoretical model results were compared. Quantitative results depicted that the mean difference between predicted and measured output air temperature in natural and forced convection scenarii is $1.47^{\circ} \mathrm{C}(3.5 \%)$ and $0.9^{\circ} \mathrm{C}(1.5 \%)$, respectively; however earlier research works and studies mentioned in literature, include error percentages in the range of $4-10 \%$. Another quantification about, the average error percentages of estimated amounts of output air velocity profile values in natural and forced convection scenarii is $9 \%$ and $4 \%$, respectively. This issue realizes that the developed model in forced convection scenario is more accurate than natural convection scenario.

\section{References}

[1] J. Bliss, The derivations of several "plate-efficiency factors" usefull in the design of flate-plate heat collectors, Solar Energy 3 (1959) 55-64

[2] S. Aboul-Enein, A.A. El-Sebaii, M.R.I. Ramadan, H.G. El-Gohary, Parametric study of a solar air heater with and without thermal storage for solar drying applications, Renew, Energy 21 (2000) 505-522 
[3] S. Janjai, N. Srisittipokakun, B.K. Bala, Experimental and modelling performances of a roof-integrated solar drying system for drying herbs and spices, Energy 33 (2008) 91-103

[4] S. Sami, N. Etesami, A. Rahimi, Energy and exergy analysis of an indirect solar cabinet dryer based on mathematical modeling results, Energy 36 (2011) 2847-2855

[5] L. Bennamoun, A. Belhamri, Design and simulation of a solar dryer for agriculture products, J. Food Eng. 59 (2003) 259-266

[6] H.P. Garg, R. Kumar, Studies on semi-cylindrical solar tunnel dryers: thermal performance of collector, Appl. Thermal Eng. 20 (2000) 115-131

[7] D. Jain, R.K. Jain, Performance evaluation of an inclined multi-pass solar air heater with in-built thermal storage on deep-bed drying application, J. Food Eng. 65 (2004) 497-509

[8] M.A. Hossain, B.K. Bala, Drying of hot chilli using solar tunnel drier, Solar Energy 8 (2007) 85-92

[9] I.N. Simate, Optimization of mixed-mode and indirectmode natural convection solar dryers, Renew. Energy 28 (2003) 435-453

[10] L. Gao, H. Bai, Sh. Mao, Potential application of glazed transpired collectors to space heating in cold climates, Energy Conversion and Management 77 (2014) 690-699

[11] M. Baritto, J. Bracamonte, A dimensionless model for the outlet temperature of a nonisothermal flat plate solar collector for air heating, Solar Energy 86 (2012) 647-653

[12] V. Delisle, M. Kummert, A novel approach to compare building-integrated photovoltaics/thermal air collectors to side-by-side PV modules and solar thermal collectors, Solar Energy 100 (2014) 50-65

[13] A. Shahsavar, M. Ameri, Experimental investigation and modeling of a direct-coupled PV/T air collector, Solar Energy 84 (2010) 1938-1958

[14] M. Ghadimi, H. Ghadamian, A.A. Hamidi, F. Fazelpour, M.A. Analysis of free and forced convection in airflow windows using numerical simulation of heat transfer, Int. J. Energy Environ. Eng. (2012) 3-14

[15] M. Ghadimi, H. Ghadamian, A.A. Hamidi, M. Shakouri, S. direct-coupled Ghahremanian,Numerical analysis and parametric study of the thermal behavior in multiple-skin facades, Energy and Buildings 67 (2013) 44-55

[16] H. Ghadamian, M. Ghadimi,M. Shakouri, M. Moghadasi, M. Moghadasi, Analytical solution for energy modeling of double skin facades building, Energy Buildings 50 (2012) $158-165$ 